\title{
Análise dos programas de plantas medicinais e fitoterápicos no Sistema Único de Saúde (SUS) sob a perspectiva territorial
}

\author{
Analysis of medicinal plant and herbal medicine programs in the \\ Unified Health System (SUS) from the territorial perspective
}

Luis Henrique Leandro Ribeiro (https://orcid.org/0000-0002-9651-553X) ${ }^{1}$

${ }^{1}$ Faculdade de Formação de Professores, Universidade do Estado do Rio de Janeiro. R. Francisco Portela 1470, Patronato. 24435-005 São Gonçalo RJ Brasil. luis.ribeiro@yahoo.com.br

\begin{abstract}
There has been significant growth in the number of municipal phytotherapy programs in the Unified Health System since the launch of the National Policy of Medicinal Plants in 2006. The aim of the research was to analyze how these programs are distributed throughout Brazil, how they express regional diversity and how land use can influence these programs and promote broad technical synergy (local knowledge and universal knowledge) and policy (strategy and actors) in the production, circulation, distribution and dispe sation of medicinal plants in the public health system. The analysis involved a theoretical framework of critical geography and public health, conceptual and thematic literature review, document analysis, survey of primary and secondary data along with extensive fieldwork. The results show that the growth of programs was accompanied by the choice of industrialized herbal medicines, spatially concentrated in the South and Southeast. Two phases were identified in this process: 19802008 characterized by horizontal actions linked to regional diversities; 2008 to the present characterized by verticalized actions on a national scale. The National Policy made it possible to increase the number of programs but did little to promote greater regional diversity.
\end{abstract}

Key words Territory, Regional diversity, Medicinal plants, Unified Health System.
Resumo É expressivo o crescimento do número de programas de fitoterapia no SUS desde 2006, quando lançada a Política Nacional de Plantas Medicinais e Fitoterápicos. Como esses programas se distribuem no território e como expressam diversidades regionais? A pesquisa analisou como os usos do território condicionam a existência desses programas e como estes promovem maior sinergia técnica (saber local e saber universalizado) e politica (estratégias e atores) na produção, circulação, distribuição e dispensação de plantas medicinais e fitoterápicos no sistema público de saúde. A análise envolveu referencial teórico da geografia crítica e saúde coletiva, revisão bibliográfica conceitual e temática, análise documental, levantamento de dados primários e secundários, destacando-se extenso trabalho de campo. Os resultados apontam que o crescimento dos programas foi acompanhado pela opção por fitoterápicos industrializados, concentrando-se espacialmente no Sul e Sudeste. Foram identificadas duas fases nesse processo: 1980-2008, caracterizada por ações mais horizontais ligadas a diversidades regionais; e 2008-atual, caracterizada por ações mais verticalizadas na escala nacional. Conclui-se: a Politica Nacional possibilitou aumento do número de programas, mas pouco fomentou suas expressões regionais.

Palavras-chave Território, Diversidade regional, Plantas medicinais, Sistema Único de Saúde 


\section{Introdução}

No período da globalização, verifica-se a valorização mundial de plantas medicinais e fitoterápicos sob novas bases. Alguns eventos globais Primeira Conferência Mundial sobre o Homem e o Meio Ambiente coordenada pela Organização das Nações Unidas (ONU) e realizada na Suécia em 1972 (Conferência de Estocolmo), marco mundial do ideário ecológico e ambientalista; e Conferência Internacional sobre Assistência Primária em Saúde realizada em Alma-Ata no Cazaquistão, em 1978, pela Organização Mundial da Saúde da Organização das Nações Unidas (OMS/ONU) - inauguraram possibilidades de novos usos e sentidos à fitoterapia, os quais têm repercutido no Brasil, desde 1980, com a difusão das práticas de Medicina Tradicional e Medicina Complementar e Alternativa.

Contudo, ressalta-se que as práticas de fitoterapia estão presentes no território brasileiro desde há muito tempo, ligadas à medicina popular e às práticas culturais ancestrais enraizadas em todas as regiões do país. A partir dos anos 1980 o ideário de um sistema público e universal de saúde, que viria inaugurar o Sistema Único de Saúde (SUS), e o uso de plantas medicinais e fitoterápicos - tanto sob as novas bases advindas de eventos globais, como aquele enraizado culturalmente nos diversos lugares do país - passam a partilhar e a convergir projetos comuns.

$\mathrm{Na}$ década de 1980, alguns municípios pioneiros apresentaram experiências de fitoterapia na saúde pública, seja de modo mais independente e local, seja como resultado do Programa de Pesquisas de Plantas Medicinais da antiga Ceme (Central de Medicamentos), primeira política de âmbito nacional do Ministério da Saúde, que vigorou oficialmente de 1982 a 1997, mas cujas ações de fato se concentraram nos anos $1980^{1}$. Nos anos 1990, após criação do Sistema Único de Saúde (SUS), com a Constituição de $1988^{2}$ e a Lei Orgânica da Saúde (Lei 8.080 de 19 de setembro de 1990$)^{3}$, registra-se o crescimento no número de programas municipais de fitoterapia, com aumento expressivo a partir de 2006, quando foi lançada a Política Nacional de Plantas Medicinais e Fitoterápicos (PNPMF) do Ministério da Saú$\mathrm{de}^{4,5}$, potencializada pela instituição do Programa Nacional de Plantas Medicinais e Fitoterápicos, e seu Comitê Nacional Gestor, em 20086,7.

Desde então, as plantas medicinais e os fitoterápicos vêm ganhando importância no âmbito da política nacional de saúde, com crescimento de investimentos e valorização de programas no
SUS. As heranças e as riquezas da diversidade territorial do país permitem a existência de uma diversidade de plantas e saberes que informam seus usos medicinais. Existe ainda uma diversidade de atores e instituições presentes nos distintos lugares e envolvidos, direta ou indiretamente, nas práticas e programas de fitoterapia. Nesse sentido, questiona-se: como os programas de fitoterapia no SUS se distribuem pelo território brasileiro e de que maneira expressam diversidades regionais?

Assim, a pesquisa buscou analisar como os usos do território ${ }^{8}$ condicionam a existência de programas de fitoterapia no SUS e como estes promovem maior sinergia técnica (saber local e saber universalizado) e política (estratégias e atores) na produção, circulação, distribuição e dispensação de plantas medicinais e fitoterápicos pelo sistema público de saúde.

O enfoque do artigo é a apresentação e discussão das duas fases identificadas na difusão dos programas municipais de fitoterapia no SUS, uma anterior à PNPMF de 2006 e outra posterior, distintas em função da opção predominante da modalidade de produção adotada pelos municípios, grosso modo, manipulada-horizontalizada e industrializada-verticalizada. Além da relação de obstáculos e dificuldades enfrentados pelos programas, de um lado, e das estratégias de manutenção e fortalecimento dos mesmos, de outro, registrados pela pesquisa durante as entrevistas nos trabalhos de campo junto a atores estatais e não estatais vinculados aos programas de fitoterapia.

\section{Método}

O caráter original e inédito da combinação de abordagens conceituais (geografia crítica e saúde coletiva) a partir da operacionalização do conceito geográfico de verticalidades e horizontalidades no território 9 (pouco usual na saúde coletiva) para analisar uma temática (a adoção de plantas medicinais e fitoterápicos pelo SUS) não abordada pela geografia em suas análises regionais, foi possível com o concurso da análise por triangulação de métodos ${ }^{10-12}$. Considerando-se também o estudo de campo, realizado em 24 municípios das quatro macrorregiões brasileiras analisadas e que totalizou 81 entrevistas, destaca-se que não foram encontrados estudos desta abrangência geográfica utilizando essas abordagens conceituais e metodológicas. Daí as especificidades dos achados e o caráter inovador da pesquisa nos cenários nacional e internacional. 
A análise por triangulação de métodos é uma estratégia de pesquisa caracterizada pela combinação e utilização, em uma única investigação, de uma variedade de métodos e de técnicas de levantamento e análise de dados e informações que torna possível apreender as dimensões qualitativas e quantitativas do estudo ${ }^{10-12}$. Ao agregar e propiciar o diálogo entre marcos teórico-conceituais de distintas áreas do conhecimento (como a geografia e a saúde coletiva) com as distintas visões de mundo dos informantes (agentes e atores) da pesquisa, essa estratégia de análise possibilita o exercício de uma ciência criativa demandante e aberta a um pluralismo metodológico e a uma multiplicidade de visões de mundo.

A partir de referencial teórico da geografia crítica e da saúde coletiva, a pesquisa envolveu revisão bibliográfica conceitual e temática, análise documental, levantamento de dados primários e secundários, destacando-se extenso trabalho de campo nas quatro macrorregiões brasileiras: $R e$ giões Concentrada, Centro-Oeste, Nordeste e Amazônia. Essa proposta de regionalização dos Quatro Brasis $^{13}$ tem como fundamento a difusão diferencial e desigual, no atual período, do meio técnicocientífico-informacional no território brasileiro em relação às heranças presentes nas distintas regiões.

Os dados secundários foram levantados através de revisão bibliográfica e documental, além daqueles fornecidos em visitas técnicas junto a gestores (federal, estadual e municipal), destacando-se os dados do Diagnóstico Situacional de Fitoterapia no SUS da Pesquisa Expertise (de 2008) e do $1^{\circ}$ Censo do Programa de Melhoria do Acesso e da Qualidade na Atenção Básica - PMAQ (de 2012) fornecidos pelo Departamento de Atenção Básica da Secretaria de Atenção à Saúde do Ministério da Saúde (DAB/SAS/MS), os quais possibilitaram a elaboração do Gráfico 1 e dos Mapas 1 e 2 apresentados mais adiante na seção Resultados.

Os dados primários foram coletados a partir da realização de trabalhos de campo nas quatro macrorregiões brasileiras privilegiando abordagem dialógica através de observação etnográfica e pesquisa-ação ${ }^{11,12}$ junto a hortos de plantas medicinais, farmácias e laboratórios públicos de manipulação de fitoterápicos, unidades de saúde, órgãos e instituições gestores, universidades e centros de pesquisa, organizações e movimentos sociais, feiras e mercados de plantas e ervas medicinais.

Foram selecionados 14 programas de fitoterapia no SUS, contemplando as quatro macrorregiões, e considerando: (i) aqueles representa- tivos, com visibilidade e referência, dos modelos de produção e dispensação de plantas medicinais e fitoterápicos; (ii) programas em município de grande porte (capital ou região metropolitana); (iii) programas em município de pequeno/médio porte (ou conjunto de municípios associados).

A seleção e a definição dos programas buscou contemplar aqueles mais representativos e de maior visibilidade conforme o critério (i), observados e escolhidos tanto na revisão bibliográfica e documental como nos relatos e depoimentos (indicados ou sugeridos pelos entrevistados) no decorrer da realização dos trabalhos de campo. Considerando esses programas de maior citação e referência buscamos contemplar a escolha de "pelo menos" dois deles para cada uma das quatro macrorregiões, sendo um programa conforme critério (ii) e outro segundo critério (iii). Objetivando com esse procedimento contemplar distintas situações geográficas nas macrorregiões segundo porte populacional e densidade técnica e política presente no município, verificando com isso a maior ou menor capacidade e autonomia do ente municipal em abrigar programas de fitoterapia no SUS. Verificou-se que tais critérios (ii e iii) embora imprimam complexidades e condições próprias aos programas, não são determinantes para a existência ou não dos mesmos, tampouco para a definição de uma tipologia de programas segundo porte do município.

Os 14 programas selecionados estavam sediados nos seguintes municípios: Oeste do Paraná (Foz do Iguaçu, Vera Cruz do Oeste e Pato Bragado); Toledo (PR); Campinas (SP); São Paulo (SP); Betim (MG); Oeste de Goiás (Diorama, Iporá, Arenópolis, Aragarças e Jussara); Goiânia (GO); Riacho Fundo (DF); Planaltina (DF); Cuiabá (MT); Brejo da Madre de Deus (PE); Fortaleza (CE); Maracanaú (CE); e Belém (PA).

Nota-se que em três macrorregiões (Região Concentrada, Centro-Oeste e Nordeste) foram selecionados mais municípios do que o previsto, o que se deve à maior presença de programas nessas macrorregiões, e em uma macrorregião (Região Amazônica) foi selecionado apenas um programa, de município de grande porte (Belém-PA), devido à dificuldade da pesquisa em planejar e realizar trabalho de campo em município de menor porte (ou conjunto de pequenos municípios) nessa macrorregião, destacando que durante a pesquisa não recebemos retorno dos agentes e instituições contatados em pequenas localidades dos estados do Acre e Amazonas que, segundo relatos, possuíam programas de fitoterapia no SUS à época. 
Também foram realizados trabalhos de campo e entrevistas em outros municípios - como Plano Piloto em Brasília (DF), Várzea Grande (MT), Cidade de Goiás (GO), Medianeira (PR), Recife (PE), Olinda (PE) e Jaboatão dos Guararapes (PE) - em virtude da importância de atores e agentes aí sediados para as políticas e programas de fitoterapia no SUS analisados, como: gestores, agências e órgãos governamentais; universidades; e organizações comunitárias e movimentos sociais.

O trabalho de campo compreendeu visitas às unidades e entrevistas junto $a$ atores $e$ agentes relevantes: (i) Gestores (municipais, estaduais e federais) ligados à saúde e outras áreas, além de técnicos administrativos e trabalhadores de secretarias, agências reguladoras, hortos de plantas medicinais, laboratórios de manipulação, farmácias básicas e unidades de saúde; (ii) Profissionais de saúde (farmacêutico, médico, enfermeiro, nutricionista e psicólogo) e outros, como assistente social, biólogo, pedagogo, engenheiro e agrônomo; (iii) Agentes vinculados à medicina popular (parteira, mateiro, vendedor ambulante, raizeiro e erveiro); (iv) Representantes do controle e participação social em conselhos de saúde (municipais e estaduais) e comitês (estaduais e federal) das políticas e programas de fitoterapia; (v) Pesquisadores de universidades, faculdades, centros e institutos de pesquisa e formação; (vi) Produtores da agricultura familiar, cooperativas e associações de agricultores, extrativistas e erveiros; (vii) Associações religiosas, pastorais de igrejas, associações de usuários do SUS, movimentos sociais (ecológicos, ambientalistas, de mulheres, de saúde da população negra e de saúde alternativa e complementar) e Organizações Não Governamentais; e (viii) Órgão de regulação e normatização (Agência Nacional de Vigilância Sanitária).

Nos roteiros semiestruturados que guiaram as entrevistas, todas presenciais, abordamos: (i) histórico profissional do entrevistado; (ii) histórico da instituição, do programa de fitoterapia ou do movimento social; (iii) principais atores envolvidos; (iv) parcerias e convênios; (v) fontes orçamentárias e de recursos (permanentes ou ocasionais); (vi) logística, etapas e atores envolvidos na produção dos insumos (produção em hortos e/ou laboratórios de manipulação; distribuição; dispensação nos serviços de saúde); (vii) avaliação das dificuldades e obstáculos dos programas; (viii) avaliação das políticas e programas federais, estaduais e municipais; (ix) referências e fontes de informação e divulgação; (x) sugestões de outros programas e experiências de fitoterapia no Brasil e outros países; (xi) sugestões bibliográficas; (xii) considerações finais do entrevistado.

No conjunto, entre agosto de 2010 e janeiro de 2014, foram realizadas 81 entrevistas em 24 municípios, de oito estados brasileiros, e três regiões administrativas do Distrito Federal, abarcando as quatro macrorregiões brasileiras.

A análise por triangulação de métodos levou à compreensão de que "dados subjetivos (significados, intencionalidade, interação, participação) e dados objetivos (indicadores, distribuição de frequência e outros) são inseparáveis e interdependentes"10. Nesse sentido, os Resultados e a Discussão a seguir revelam o papel fundamental do olhar do pesquisador - através da escolha das metodologias, da forma de análise, da interpretação e da exposição - na condução do estudo e na elaboração dos achados e resultados ${ }^{12}$. Ademais, por se tratar de processo dialético e, também, dialógico, as reflexões e sínteses teóricas da análise apresentadas a seguir constituem amálgamas nos quais se faz presente os sentidos e a participação do Outro, os agentes e atores em seu conjunto.

\section{Resultados}

Verificou-se que o número de programas de fitoterapia vem aumentado desde meados dos anos 1980. Mas, é a partir dos anos 1990, após a criação do SUS em 1988, que se registra taxa crescente no número dos programas. Este crescimento acentua-se a partir de 2006-2008, com o lançamento da Política Nacional de Plantas Medicinais e Fitoterápicos do Ministério da Saúde (2006) e do Programa Nacional de Plantas Medicinais e Fitoterápicos e do seu Comitê Gestor, em 2008. Dados do Ministério da Saúde mostram que: em 1997, 101 municípios apresentavam programas; em 2004 eram 116 municípios; saltando para 346 municípios, em 2008; e alcançando 815 municípios em 2012 (Gráfico 1).

Quando se analisa as modalidades de produção dos programas municipais de fitoterapia no SUS, comparando os anos de 2008 e 2012 (Figura 1 e Figura 2, respectivamente), observa-se que havia um predomínio, até 2008, de programas municipais fundamentados na manipulação de fitoterápicos $(80,2 \%)$, sobretudo em farmácias públicas próprias de manipulação $(45,7 \%$ do total dos programas municipais) e, em menor grau, em farmácias privadas conveniadas (34,5\%). Já a compra e a dispensação de fitoterápicos industrializados, muito menos expressivos em 2008 (19,8\% dos programas municipais apresentavam essa 


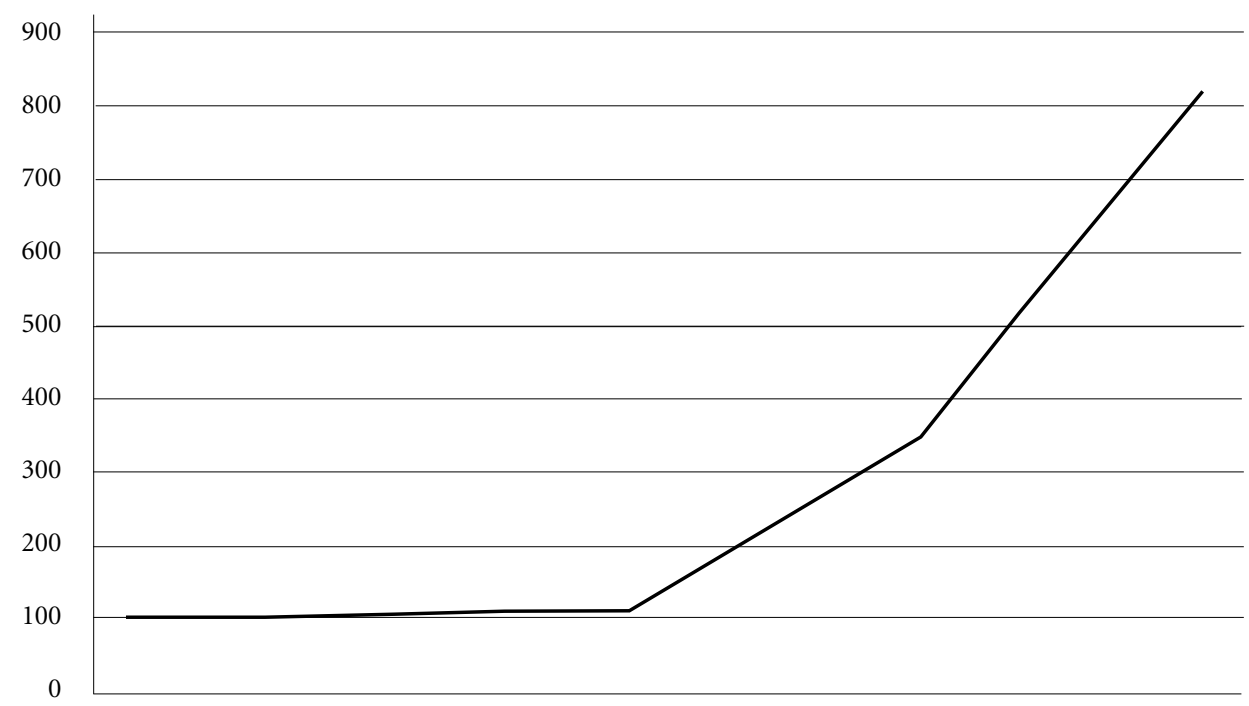

$1997 \quad 199819992000 \quad 2001200220032004 \quad 20052006200720082009201020112012$

Gráfico 1. Crescimento do número de programas municipais de fitoterapia no SUS no período 1997-2012.

Fonte: elaboração própria a partir de dados das seguintes fontes: Brasil ${ }^{14}$ para dados de 1997; Torres $^{15}$ e Brasil ${ }^{16}$ para 2004; Pesquisa Expertise (para 2008); e Banco de Dados do $1{ }^{\circ}$ Censo do Programa de Melhoria do Acesso e da Qualidade na Atenção Básica (para 2012) fornecidos pelo Departamento de Atenção Básica da Secretaria de Atenção à Saúde do Ministério da Saúde (DAB/SAS/MS).

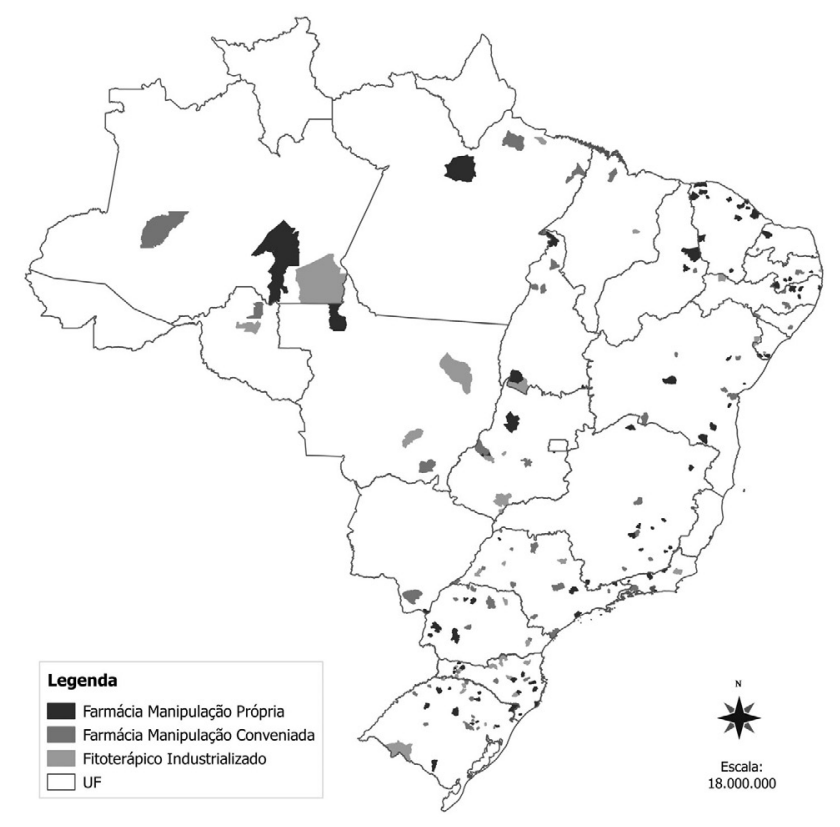

Figura 1. Brasil: municípios com fitoterapia no SUS, segundo três modalidades de produção (farmácia própria de manipulação, farmácia conveniada e fitoterápico industrializado) em 2008.

Fonte: Elaboração própria. Os 192 municípios que garantiam as plantas medicinais e os fitoterápicos no SUS (do universo de cerca de 350 que registraram serviços de fitoterapia no sistema), segundo três modalidades de produção (farmácia própria de manipulação, farmácia conveniada e fitoterápico industrializado) foram levantados no âmbito do Diagnóstico Situacional de Fitoterapia no SUS de 2008 realizado pela empresa Expertise, coordenado pelo Departamento de Atenção Básica da Secretaria de Atenção à Saúde do Ministério da Saúde (DAB/SAS/MS), cedido ao pesquisador pela Coordenação Geral de Áreas Técnicas (CGAT) do DAB/SAS/MS. 


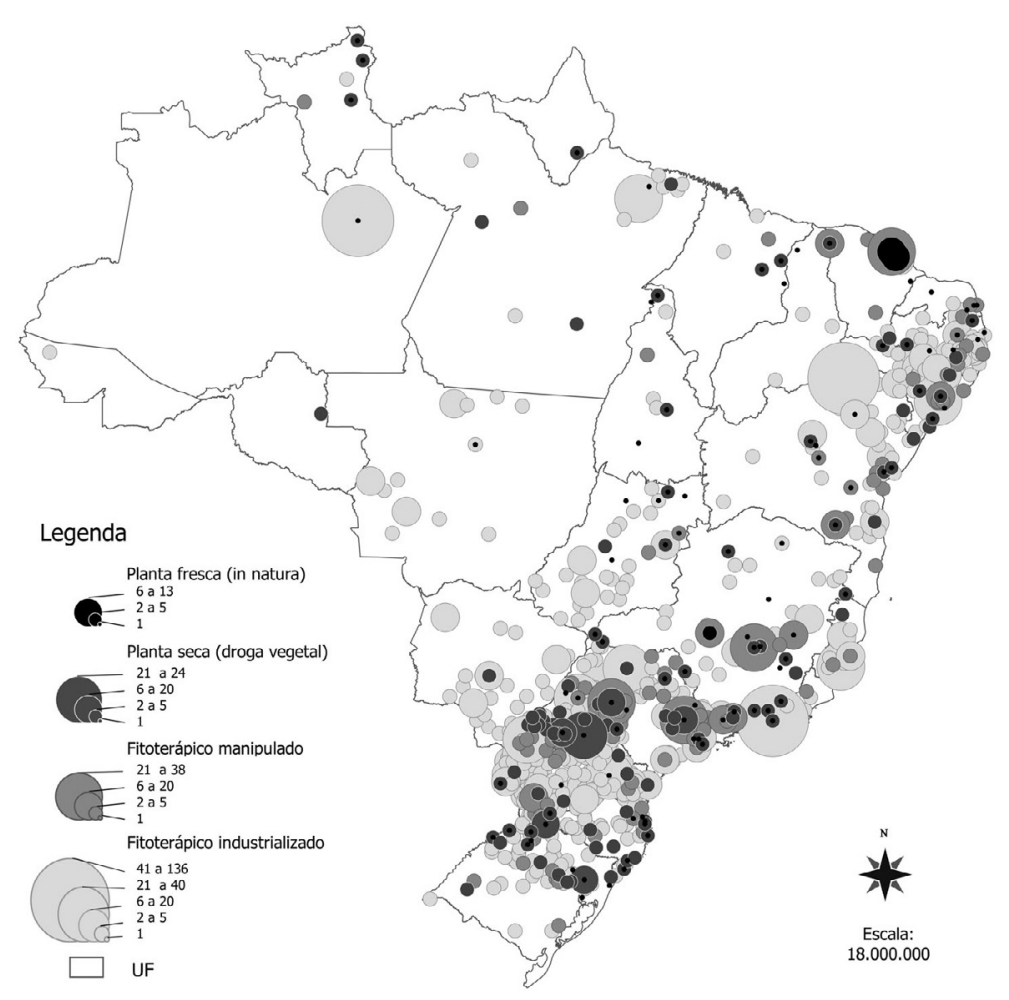

Figura 2. Brasil: estabelecimentos municipais com fitoterapia no SUS por município, segundo quatro modalidades de produção (planta fresca, planta seca, fitoterápico manipulado e fitoterápico industrializado) em 2012.

Fonte: Elaboração própria. Os 3.152 estabelecimentos de saúde presentes em 815 municípios foram levantados no âmbito das pesquisas Censo da Infraestrutura dos Estabelecimentos de Saúde e $1^{\circ}$ Ciclo do Programa Nacional de Melhoria do Acesso e da Qualidade da Atenção Básica (PMAQ-AB), de 2012, coordenadas pelo Departamento de Atenção Básica da Secretaria de Atenção à Saúde do Ministério da Saúde (DAB/SAS/MS), dados cedidos ao pesquisador pela Coordenação Geral de Áreas Técnicas (CGAT) do DAB/SAS/MS.

modalidade de produção e dispensação), torna-se predominante nos programas municipais a partir de 2012 (presente em 64,3\% dos municípios com programas) com forte recuo dos fitoterápicos manipulados $(15,8 \%)$, tanto em farmácias públicas próprias como em conveniadas, e da dispensação de plantas frescas $(9,1 \%)$ e secas $(10,8 \%)$.

Ademais, verifica-se que a concentração espacial em porções das Regiões Sul e Sudeste (Região Concentrada do país) dos programas existentes se acentua em 2012, quando comparada com a distribuição dos programas menos concentrada no território nacional em 2008.

Embora os mapas tenham sido elaborados a partir de dados de duas fontes diferentes, com metodologias e critérios distintos de mensuração, eles ilustram e corroboraram os dados primários levantados pela pesquisa através dos depoimen- tos, avaliações e afirmações dos atores nas entrevistas dos trabalhos de campo realizados nas quatro macrorregiões do país. O que permitiu a identificação e definição de duas fases - quantitativa e qualitativamente distintas - na difusão dos programas de fitoterapia no SUS em função da opção predominante da modalidade de produção, grosso modo: (i) manipulada e horizontalizada; e (ii) industrializada e verticalizada. O que será discutido na seção seguinte.

Importante registro da pesquisa durante os trabalhos de campo e entrevistas, e que deve ser destacado, é que apesar do crescimento contínuo do número de programas em todo o Brasil, em taxas mais intensas a partir de 2006-2008, verificou-se, por outro lado, um histórico e uma taxa elevada de mortalidade, interrupções e descontinuidades dos programas de fitoterapia. 
Dentre os constrangimentos e as dificuldades que justificam tal situação, conforme apontados pelos entrevistados, destacam-se: (i) descontinuidades e rupturas em função de mudanças no governo municipal e resistência dos gestores; (ii) falta de controle sobre matéria-prima e dificuldades de compra e aquisição no mercado dos insumos (plantas medicinais, drogas vegetais, extratos e fitoterápicos industrializados) devido a fornecedores não qualificados e matéria-prima de má qualidade; (iii) inexistência de recursos próprios garantidos por lei no orçamento e exclusivo à manutenção e expansão do serviço de fitoterapia no SUS, acentuando dependência da conjuntura política e de agentes da gestão administrativa; (iv) dificuldades e entraves para aquisição dos insumos vegetais ou medicamentos fitoterápicos acabados através do marco regulatório das compras públicas (processos licitatórios); (v) resistência da classe médica em aderir e apoiar os programas de fitoterapia; (vi) falta de espaço físico, local apropriado, estruturas e equipamentos para operação dos programas (escritórios e locais administrativos; laboratórios e farmácias de manipulação; hortos e terrenos para produção de massa verde); (vii) rigidez normativa e falta de regulação e normatização mais adequadas e sensíveis às realidades regionais e locais dos programas de fitoterapia, sobretudo por parte da Agência Nacional de Vigilância Sanitária (Anvisa) e, em menor grau, por algumas ações do Ministério da Saúde, como as relações nacionais de referência para plantas medicinais e medicamentos fitoterápicos.

Por outro lado, dentre as principais estratégias de manutenção e fortalecimento dos programas de fitoterapia no SUS apontadas pelos entrevistados, destacam-se: (i) apoio e pressão da população, tanto espontânea quanto de forma mais organizada: associações de usuários, de profissionais e de entidades religiosas; movimentos sociais; ou nas representações de controle social do SUS, como os Conselhos de Saúde (municipais, estaduais e nacional); (ii) institucionalização através de leis, decretos e portarias (municipais, estaduais e federais) para garantir continuidade, permanência e recursos orçamentários próprios; (iii) elaboração e prestação de cursos de capacitação em fitoterapia para gestores, profissionais e trabalhadores da saúde e de outras áreas, para a população em geral, além de cursos para capacitação de atores vinculados à produção de plantas medicinais (produtores agrícolas) e manipulação de fitoterápicos; (iv) promoção e realização de eventos e campanhas públicas de divulgação e fomento dos programas e da fitoterapia de um modo geral (oficinas, encontros, seminários, semanas, comemorações e rodas de conversa); (v) tornar-se Farmácia Viva ${ }^{17}$, modelo que incorpora e internaliza as etapas de produção e dispensação de plantas medicinais e fitoterápicos (cultivo, hortos próprios ou comunitários credenciados, beneficiamento, elaboração de fitoterápicos em farmácias e oficinas de manipulação próprias, e dispensação dos insumos na rede de saúde); (vi) regionalização dos programas de fitoterapia, por meio de ações e políticas do governo federal, mas principalmente através de políticas estaduais e da própria articulação e cooperação entre os programas municipais; (vii) levantamentos e estudos para demonstrar custo-efetividade da utilização de plantas medicinais e fitoterápicos pelo sistema de saúde, a fim de fortalecer legitimidade e atratividade dos programas junto aos gestores do SUS; e (viii) parcerias e convênios com universidades e centros de pesquisa para expandir as ações, os produtos e dar legitimidade técnica, científica, informacional e normativa aos programas.

\section{Discussão}

Com base nos resultados encontrados, foi possível identificar duas fases na difusão dos programas de fitoterapia no SUS, discutidas a seguir a partir do par conceitual analítico verticalidades e horizontalidades 9 . Marco teórico conceitual que permite a leitura do processo contínuo e sempre aberto de formação dos lugares e regiões. Se de um lado há vetores mais externos aos lugares nos quais predomina um caráter mais homogeneizador, uma racionalidade dominante e universalizada marcada por solidariedades de cunho mais organizacional para a qual o território importa mais como recurso, pontos e locais estratégicos, por outro, os lugares abrigam uma força emanada de horizontalidades fundadas na proximidade, na contiguidade, na vizinhança, no cotidiano compartido, nas temporalidades e racionalidades diversas, uma heterogeneidade criadora cujas solidariedades tanto obrigadas quanto desejadas são produtoras de novas possibilidades de existência.

A primeira fase compreende de meados da década de 1980, início dos programas de fitoterapia na saúde pública, a 2008, quando é lançado o Programa Nacional de Plantas Medicinais e Fitoterápicos no âmbito do SUS. Essa primeira fase se caracteriza pelo predomínio de programas de fitoterapia fundamentados em hortos públicos e comunitários, em farmácias públicas municipais 
de manipulação de fitoterápicos e, em menor número, em convênios com farmácias de manipulação privadas. Trata-se de um tipo mais horizontalizado de programa, cuja sistematicidade ${ }^{18}$ ao incorporar as heranças institucionais e culturais do lugar tende a imprimir aos programas um caráter mais regional, político, pedagógico e plural (em termos de cultura, técnica, práticas de saúde, espécies de plantas, estratégias políticas e atores produtivos envolvidos). Esse tipo de programa coaduna com uma concepção mais ampliada de saúde e de sistema de saúde ${ }^{19,20}$, pois vai além da concepção médico-assistencial, de saúde como mera ausência de doença, de cuidado individual e foco setorial dos processos de saúde e doença. Configura um modelo mais próximo à prática $\mathrm{e}$ ao ideário do Movimento da Reforma Sanitária que preconiza o SUS também como espaço de emancipação e transformação política ${ }^{21}$.

O lançamento da Política Nacional de Plantas Medicinais e Fitoterápicos, em 2006, representa uma transição na sistematicidade predominante dos programas, visível a partir dos modelos de produção e dispensação de plantas medicinais e fitoterápicos dos mesmos. Sendo que em 2008, após instituição do Programa Nacional de Plantas Medicinais e Fitoterápicos, inicia-se a segunda fase da difusão dos programas de fitoterapia no SUS, caracterizada pelo crescimento acentuado da criação de programas no país, tendo como base predominante a compra e a dispensação de fitoterápicos industrializados. São programas de tipo mais verticalizados, isto é, menos vinculados às heranças e diversidades regionais e institucionais dos serviços de saúde, à diversidade das práticas populares, das espécies vegetais utilizadas e às estratégias políticas e produtivas dos diversos atores e agentes do lugar. Uma sistematicidade organizada muito mais em uma escala nacional e que tem imprimido aos programas um caráter mais próximo da lógica e do uso hegemônico vinculados à biomedicina, à produção industrializada e à comercialização de produtos mais difundidos em todo o território nacional. Um processo, em certa medida, de modulação, cooptação ou mesmo incorporação dos programas pela sistematicidade da biomedicina, compreendida como um arranjo territorial caracterizado pela associação e vínculos entre medicina técnico-científica, corporação médica, corporações empresariais do grande capital e Estado ${ }^{22}$.

Essa tensão entre sistematicidades, sentidos das ações, modelos de produção e dispensação, verticalidades e horizontalidades, bem como a apresentação e a descrição das diversidades envolvidas - cultural, social, econômica, política, heranças, atores, agentes, práticas e espécies vegetais utilizadas - estão mais bem detalhadas, descritas e podem ser conferidas e consultadas em trabalhos publicados ${ }^{22,23}$.

\section{Conclusões}

A pesquisa verificou que os programas municipais de fitoterapia no SUS nas regiões brasileiras se vinculam a uma pluralidade de atores, práticas, saberes e estratégias. $\mathrm{O}$ valor e a riqueza que eles representam advém dos diversos usos das plantas. Tais usos envolvem uma biodiversidade e também uma sociodiversidade que são recíprocas, isto é, dependentes e indissociáveis, historicamente elaboradas e espacialmente situadas.

É fato que a Política Nacional de Plantas Medicinais e Fitoterápicos, de 2006, e o Programa Nacional de Plantas Medicinais e Fitoterápicos, de 2008, representaram um enorme ganho para as práticas de fitoterapia no SUS, vide o crescimento expressivo no número de programas em todo o país a partir de 2006. Porém, essa mesma política não necessariamente tem contribuído para reforçar a biodiversidade e a sociodiversidade regional dos programas. Pois esse crescimento no número de programas, fundamentado no predomínio e massificação dos fitoterápicos industrializados - verificado na segunda fase da difusão dos programas (pós PNPMF de 2006) -, é acompanhado de um processo de redução da diversidade territorial em virtude do alijamento da participação mais ampla de usos, atores, agentes, culturas, práticas, economias, saberes, espécies e estratégias expressivos das horizontalidades presentes nos lugares do país, o que caracterizava a primeira fase na difusão dos programas que vigorou de meados da década de 1980 até a PNPMF de 2006.

Portanto, se por um lado a Política Nacional possibilitou um aumento expressivo no número de programas de fitoterapia no SUS existentes no país, por outro lado, pouco fomentou suas expressões regionais e a incorporação das horizontalidades dos lugares nas políticas (em âmbito nacional e municipal). Ademais, também intensificou e propiciou a manutenção da concentração espacial dos programas municipais de fitoterapia em algumas porções das regiões Sul e Sudeste do país favorecendo a existência da Região Concentrada. 


\section{Agradecimentos}

À Fundação de Amparo à Pesquisa do Estado de São Paulo (Fapesp) pelas bolsas de pesquisa concedias no período de agosto de 2010 a agosto de 2014. À Coordenação Geral de Áreas Técnicas (CGAT) do Departamento de Atenção Básica da Secretaria de Atenção à Saúde do Ministério da Saúde (DAB/SAS/MS) pelos dados cedidos. Às instituições, organizações e movimentos sociais que receberam e colaboraram com a pesquisa nas diversas regiões do país durante o trabalho de campo e aos seus atores e representantes que gentilmente concederam entrevistas.

\section{Referências}

1. Brasil. Ministério da Saúde (MS). A fitoterapia no SUS e o Programa de Pesquisa de Plantas Medicinais da Central de Medicamentos. Brasília: MS; 2006. (Série B. Textos Básicos de Saúde).

2. Brasil. Constituição da República Federativa do Brasil. 5a ed. São Paulo: Editora Revista dos Tribunais; 2008.

3. Brasil. Lei No 8.080, de 19 de setembro de 1990. Dispõe sobre as condições para a promoção, proteção e recuperação da saúde, a organização e o funcionamento dos serviços correspondentes e dá outras providências. $D i$ ário Oficial da União 1990; 20 set.

4. Brasil. Decreto Presidencial no 5.813, de 22 de junho de 2006. Aprova a Política Nacional de Plantas Medicinais e Fitoterápicos. Diário Oficial da União 2006; 23 jun.

5. Brasil. Ministério da Saúde (MS). Política Nacional de Plantas Medicinais e Fitoterápicos. Brasília: MS; 2006. (Série B. Textos Básicos de Saúde)

6. Brasil. Ministério da Saúde (MS). Portaria Interministerial no 2.960, de 9 de dezembro de 2008. Aprova o Programa Nacional de Plantas Medicinais e Fitoterápicos e cria o Comitê Nacional de Plantas Medicinais e Fitoterápicos. Diário Oficial da União 2008; $10 \mathrm{dez}$.

7. Brasil. Ministério da Saúde (MS). Programa Nacional de Plantas Medicinais e Fitoterápicos. Brasília: MS; 2009. (Série C. Projetos, Programas e Relatórios).

8. Santos M. O retorno do território. In: Santos M, Souza, MAA, Silveira, ML, organizadores. Território: globalização e fragmentação. São Paulo: Hucitec; 1994. p.15-20.

9. Santos M. A natureza do espaço: técnica e tempo - razão e emoção. $3^{\text {a }}$ ed. São Paulo: Hucitec; 1999.

10. Minayo MCS. Introdução - Conceito de avaliação por triangulação de métodos. In: Minayo MCS, Assis SG, Souza ER, organizadores. Avaliação por triangulação de métodos: abordagem de programas sociais. Rio de Janeiro: Fiocruz; 2005. p. 19-51.

11. Duarte T. A possibilidade da investigação a 3: reflexões sobre triangulação (metodológica). CIES e-WORKING PAPER, Lisboa: Centro de Investigação e Estudos de Sociologia, Instituto Superior de Ciências do Trabalho e da Empresa; 2009.

12. Tuzzo AS, Braga CF. O processo de triangulação da pesquisa qualitativa: o metafenômeno como gênese. Revista Pesquisa Qualitativa 2016; 5(4):140-158.

13. Santos M, Silveira ML. O Brasil: território e sociedade no início do século XXI. Rio de Janeiro: Editora Record; 2001.

14. Brasil. Ministério da Saúde (MS). Proposta de Política Nacional de Plantas Medicinais e Medicamentos Fitoterápicos. Brasília: MS; 2001.

15. Torres KR. Política Nacional de Plantas Medicinais e Fitoterápicos. Departamento de Assistência Farmacêutica da Secretaria de Ciência, Tecnologia e Insumos Estratégicos do Ministério da Saúde. In: III EnFarMed; setembro de 2009; São Paulo (SP). p.1-35.

16. Brasil. Ministério da Saúde (MS). Práticas integrativas e complementares: plantas medicinais e fitoterapia na Atenção Básica. Brasília: MS; 2012. (Série A. Normas e Manuais Técnicos) (Cadernos de Atenção Básica; n. $31)$.

17. Brasil. Ministério da Saúde (MS). Portaria no 886/GM/ MS, de 20 de abril de 2010. Institui a Farmácia Viva no âmbito do Sistema Único de Saúde (SUS). Diário Oficial da União 2010; 22 abr. 
18. Ribeiro ACT. Teorias da Ação. Apostila com transcrição do Curso Teorias da Ação ministrado na Universidade Estadual de Campinas. Campinas, SP: Unicamp, 18 a 22 de novembro de 2002.

19. Scliar M. História do Conceito de Saúde. PHYSIS: Rev. Saúde Coletiva, Rio de Janeiro, 2007; 17(1):29-41.

20. Almeida-Filho N. O que é Saúde? Rio de Janeiro: Editora Fiocruz; 2011.

21. Paim JS. Reforma sanitária brasileira: contribuição para a compreensão e crítica [tese]. Salvador: Universidade Federal da Bahia; 2007.

22. Ribeiro LHL. Território e macrossistema de saúde: os programas de fitoterapia no Sistema Único de Saúde (SUS) [tese]. Campinas (SP): Universidade Estadual de Campinas; 2015.

23. Cataia MA, Ribeiro LHL. Análise de Situações Geográficas: notas sobre metodologia de pesquisa em Geografia. Revista da ANPEGE 2015; (11):9-30.

Artigo apresentado em 29/03/2017

Aprovado em 21/08/2017

Versão final apresentada em 23/08/2017 